\title{
TrainME (Training Management Endeavors): A Web-based Training Needs Assessment and Management System (The Development Process)
}

\author{
Wenda D. Panes, Romel S. Mejos \\ Assistant Professor IV, College of Computer Studies, Iloilo State College of Fisheries - San Enrique Campus \\ Instructor I, College of Computer Studies, Palompon Institute of Technology - Tabango Campus \\ San Enrique, Iloilo, Philippines \\ Tabango, Palompon, Leyte, Philippines
}

\begin{abstract}
TrainME is a web-based and mobile-responsive system that addresses the training needs assessment and management concerns of the Office of Extension Services and Community Development that community-based clients to submit their profile and convey interest in training areas; notifies registered trainers to accept a lecturer task, view clients' information, and download training documents; and provides a dashboard for system administrator to manage the training programs, trainers, schedule, notifications, and reports via a web-based application. The waterfall model of Systems Development Life Cycle served as the guiding methodology in developing the system while the IEEE standard format for documentation was employed in writing the SRS, SPMP, $S D D$ and STD. The system was subjected to use case testing by the office of the extension services staff. Result of the use case testing showed that the application meet the requirements, indicated as "Passed" set by the clients. Graphical data representation, opinion mining, and word cloud generation are some of the recommendations noted for future improvements of the project.
\end{abstract}

Keywords-training, training needs, clients, trainers, assessment, management, web-based

\section{Introduction}

Practically, everyone is a student whose learning is a continuous process. No matter how brilliant a teacher is, he still needs retooling of his skills to meet the demands of his digital age students. Local government employees as well need the same in the conduct of public service. The farmers, fishermen, housewives, out-of-school youth, persons with disability, senior citizens, indigenous people, vendors etc. are also in dire need of trainings to improve farming and fishing practices, household management, and engage in self-employment. The good thing is, there are numerous trainers and extension workers in state colleges who are willing to share their expertise and extend training services to these people. However, they do not have readily-available information on what to train, when to train and who to train. They still need to conduct the preliminary activities which require time, effort and money before an actual service is rendered. This painful scenario triggered the development of TrainME(Training Management Endeavors) which aimed to aid the office of Extension Services and Community Development of State Universities and Colleges in an effective and efficient training needs assessment and management tasks.

\section{Methodology}

\section{A. Objectives of the Study}

Generally, this study aimed to develop a web-based and mobile-responsive system that will maintain the Clients, Trainers, Training Needs, Training Programs, Schedules and Notifications, and Reports and determine its user acceptability.

Specifically, the study aimed to:

(C) 2019, IJSMS 
1. Design a system with features outlined as follows:

I. Web Application

A. Admin privileges:

a. Register qualified trainers

b. Manage the following records:

i. Training Areas (Agriculture, Functional Literacy, Computer Literacy, Livelihood Projects, TESDA Training Programs)

ii. Training Programs (Agriculture: Organic Farming, Urban Gardening, Pest Control and Management, Vermicomposting, etc. Computer Literacy: Word Processing, Electronic Spreadsheet, Desktop Publishing, Presentation Packages, Web Development, etc. Livelihood: Trash to Cash, Food Processing, Baking, etc.)

iii. Training Schedule

iv. Clients and Trainers

v. Notifications

vi. Reports by:

1. Client Category

2. Location

3. Training Needs Assessment

B. Client Privileges:

a. Register Profile and Training Needs

b. Convey Interest in Training Programs

c. Receive Notifications

d. Evaluate a Training Program

C. Trainer Privileges:
a. Access Client Information
b. Confirm Trainer Task/ Receive Notifications
c. View/Download/Print Reports

II. Determine the use case testing if the applications meet the requirements set by the client.

\section{B. Scope and Limitations of the Study}

TrainME is developed to address the training assessment and management needs of the Office of Extension Services and Community Development (OESCD) of State Colleges and Universities (SUC). It was conducted at Palompon Institute of Technology - Tabango Campus and Iloilo State mcollege of Fisheries - San Enrique Campus from June 2018 to September 2018. The system was developed employing the waterfall model of System Development Life Cycle (SDLC) and utilizing software and programming tools such as PHP, MYSQL, HTML, CSS, and bootstrap. The developed system was subjected to use case testing administered to the OESCD staff.

\section{Process Model}

The main process model for this project was a variation of the waterfall model as shown in Figure 1, which includes overlapping phases, feedback loops, and prototypes. The succeeding phases may commence even if the previous phase is not yet completed as long as feedbacks are echoed to the preceding phases. Also, each phase is expected to produce a deliverable as indicated. Moreover, the Interface and Functional Prototypes enclosed in dashed border are referred to as internal deliverables, thus, they will not be given to the client. Whereas, the Product Reference Manual and User Guide are part of Product Software deliverable, thus they are delivered to the client along with the developed system. 


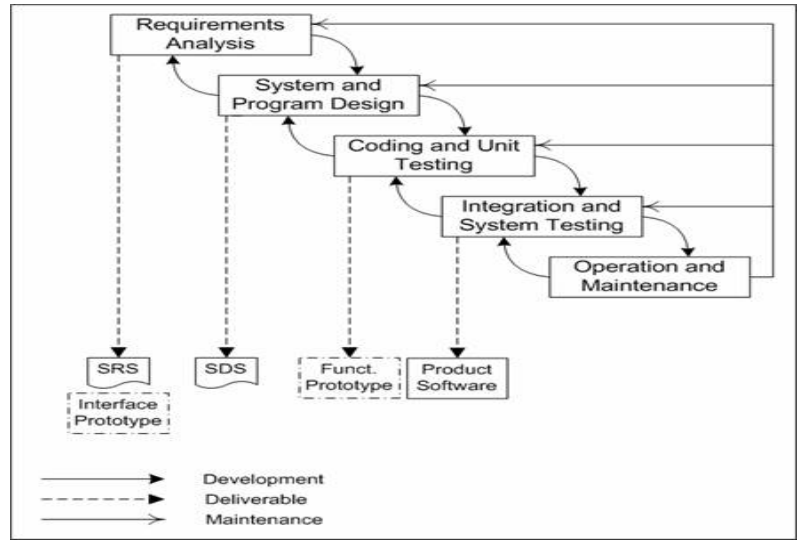

Figure 1. Software Development Waterfall Model

TrainME used TeamGantt management tool as a guide in project development. The five phases of the Waterfall model are laid out as well as the specific tasks for each phase. The detail discussion and description for each phase are narrated as follows:

1) Requirements Analysis Phase: During this phase, the project manager conducted user and system requirements analysis. Required documents such as Training Needs Assessment Survey Form, Training Designs, Training Programs, Memoranda of Agreement/Understanding were gathered. Then, business rules were determined by looking into the Extension Manual and Procedures in the Conduct of Extension Services from the OESCD. To further understand the requirements, a series of interview were conducted with the Research and Extension Chair and Staff, faculty-trainers as well as selected clients. For an in-depth understanding of processes, research on mandates, training needs, clients/beneficiaries, and funding agencies was conducted. Further, activities before, during and after the training were keenly observed.

To determine system needs, the project manager drafted the External Interface Requirements involving user, hardware, software and communication requirements. Functional requirements in the form of use case diagrams were designed using an appropriate UML designing software. Consequently, performance requirements were identified.

2) Systemand Program Design Phase: Prototyping, class diagram design, data flow diagram design as well as database design were performed in this phase. To produce a low-fidelity feel of the system to be developed, a paper prototype was created and use case diagrams were designed based on the paper prototype. This was subjected to usability test to target users. After which, class diagrams were created following the model-view-controller framework. Subsequently, sequence diagrams were designed using the Astah Community software tool. The data inputs, processes and outputs were determined with the help of data flow diagrams. Finally, the normalized and relational system database was designed using MySQL.

3) Coding and Unit Testing: In this phase of the waterfall model, four major sub-tasks were performed namely: front-end implementation, database implementation, back-end implementation and network set-up. The project manager who also assumes the roles of GUI designer and project developer started with implementing the system admin interface, trainer interface and client interface using the HTML, CSS, java script and bootstrap technologies. Appropriate and required queries were coded to extract data from the database. As to how data should behave given different transactions, such as create, read, update, send, store, print, organize, compute, match, etc. were coded meticulously, and logically following the syntactic rules of PHP programming language. Since there are three different types of users with unique system accessibility permissions, a network was set-up to have the system run simultaneously on at least three devices. Specific codes were embedded to enable multi-user web access of the system. 
4) Integration and System Testing Phase: This phase is also known as VV and the project manager who is also a QA tester performed three major tasks. First, White Box testing where the system functionality is tested and this is done by feeding the system with valid inputs. But before that, test case and procedures were drafted, test criteria were decided upon, system features to be tested were identified and test design identifier wasdetermined. Second, Black Box testing by which invalid inputs are used to test the system functionality. A test log was drafted for this task. Finally, the system a subjected to User Acceptability testing. This is done by first designing test questionnaires, then drafting user acceptance test log, determining respondents, administering the usability test and finally analyzing and interpreting the results.

5)Operation and Maintenance: This phase requires four major tasks each of which contain a number of specific activities. During the Training and Dissemination, system users must be trained on how to manipulate and navigate the system. Separate trainings will be conducted for admins, trainers, and clients. Permission from proper authorities will be sought and training module will be prepared.

A considerable amount of time is allotted for the documentation task which occurs all throughout the project development but will formally be organized on a specified time as reflected in the WBS. Document deliverables include Software Requirements Specification which lays out functional and nonfunctional requirements, and may include a set of use cases that describe user interactions that the software must provide; Software Project Management Plan that comprises of a number of activities, which contains planning of project, deciding scope of software product, estimation of cost, etc.; Software Design Description that servers as the overall guidance to the architecture of the software project; and Software Test Description that describesthe test preparations, testcases, and test procedures to be used to perform qualification testing.

User support tasks are also performed in this phase. A User Manual is drafted to serve as reference for users on the vital information about the system as well as how the system is operated. Installation requirements and dependencies are also reflected in this document. For more visual users, a video of the system walkthrough or demonstration will be developed. A website dedicated for inquiries request and response may also be designed. Finally, Nice-to-Haves features may be incorporated if time permits.

\section{Results and Discussions}

\section{A. The developed TrainME system}

TrainMe provides three modules for Admin, Trainer, and Client users loaded with features as declared in the requirements specification.

1) The Admin Log-in Interface: The Admin Login Interface reflected in Figure 2 allows an authorized user to enter a matched username and password. A confirmation message is shown upon successful login. The Continue button links to Admin Homepage.

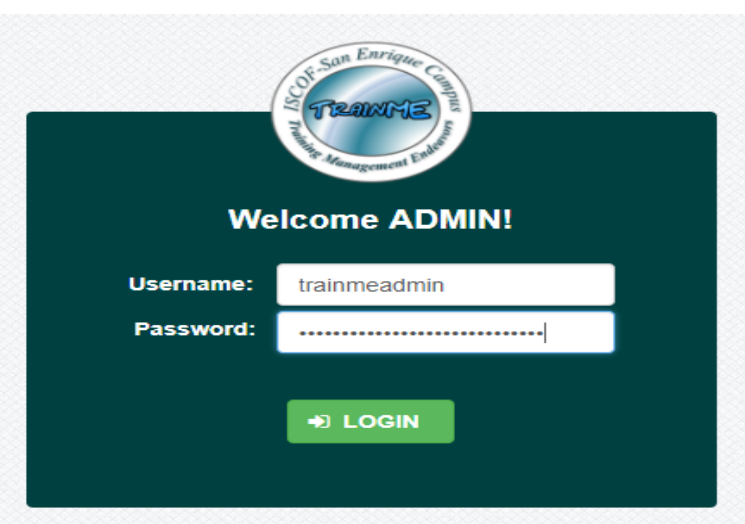

Figure 2.Admin Login Interface 
2) The Training Status/Admin Home Page:As reflected in Figure 3, the Admin Home Page contains Home, Clients, Trainers, Training Needs, Notifications, Reports, Settings, and Profile navigation menus. It displays the scheduled training programs with status as to pending, ongoing, conducted, terminated. A rating for each terminated program is also revealed.

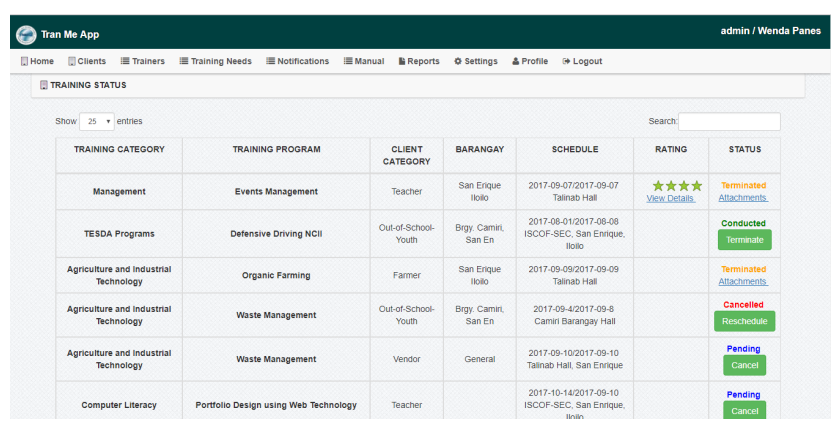

Figure 3.Home Page/Training Status

3) The Trainer Home Page: The Trainer Home Page shown in Figure 4 displays the information of training program/s conducted by a trainer.

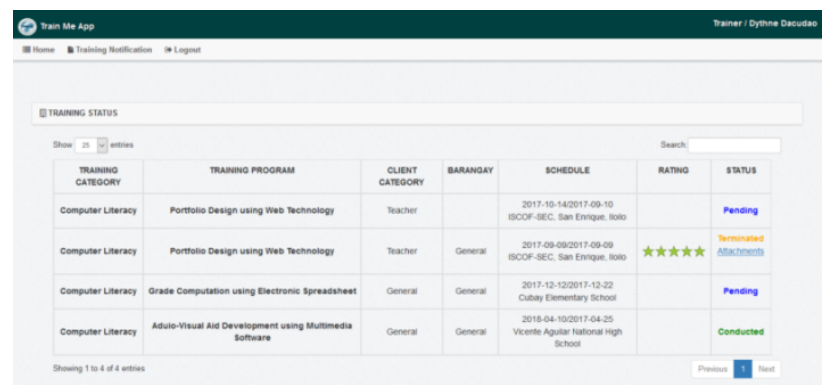

Figure 4. Trainer Home Page

4) The Client Home Page: The Client Home Page as reflected in Figure 5provides links tothe training needs of the client, the notifications, evaluation sheets for rating as well as the profile.

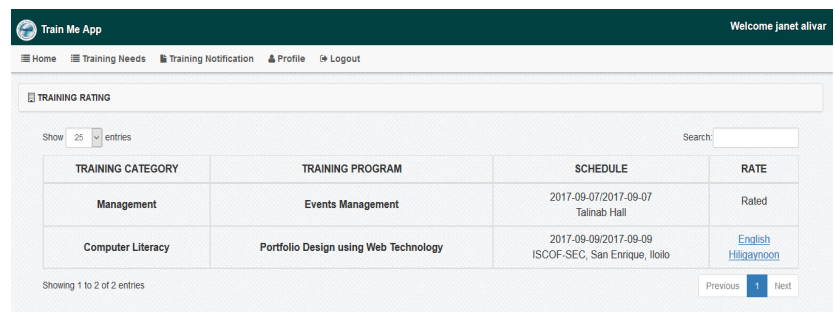

Figure 5.ClientHome Page

5) The Rating Summary Report: The Rating Summary report reflected in Figure 6 encapsulates the evaluation tendered by the clients for a particular training program for the trainer's perusal. 


\begin{tabular}{|c|c|c|c|}
\hline \multicolumn{4}{|c|}{$\begin{array}{l}\text { Office of the Extension Services } \\
\text { CLIENT RATING SUMMARY }\end{array}$} \\
\hline $\begin{array}{l}\text { Training Program: } \\
\text { Venue: } \\
\text { Inclusive Date: } \\
\text { Client Category: }\end{array}$ & $\begin{array}{l}\text { Events Management } \\
\text { Talinab Hall } \\
\text { 2017-09-07/ 2017-09-07 } \\
\text { Teacher }\end{array}$ & & \\
\hline & QUESTIONS & $\begin{array}{lllll}1 & 2 & 3 & 4 & 5\end{array}$ & AVERAGE \\
\hline \multicolumn{2}{|c|}{$\begin{array}{l}\text { QUESTIONS } \\
\text { The training met my expectations. }\end{array}$} & $\begin{array}{lllllllll}0 & 0 & 0 & 4 & 3\end{array}$ & 4.4285714285714 \\
\hline \multicolumn{2}{|c|}{ The content was helpful. } & $\begin{array}{lllllllll}0 & 1 & 0 & 2 & 4\end{array}$ & 4.2857142857143 \\
\hline \multicolumn{2}{|c|}{ The format was eajoyable. } & $\begin{array}{llllllll}0 & 0 & 1 & 3 & 3\end{array}$ & 4.2857142857143 \\
\hline \multicolumn{2}{|c|}{ The trainer had a good understanding of the topics. } & 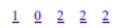 & 3.5714285714286 \\
\hline \multicolumn{2}{|c|}{ The length of the training was appropriate. } & $\begin{array}{llllll}0 & 0 & 0 & 0 & 1\end{array}$ & 5 \\
\hline \multicolumn{4}{|l|}{ No of Clients: 7} \\
\hline \multicolumn{4}{|c|}{ Total Average: 4.3142857142857} \\
\hline
\end{tabular}

Figure 6. Rating Summary Report

\section{B. Result of use case testing}

To evaluate if the application meet the requirements set by the client the developer designed a use case testing toolTable I, Table II, and Table III reflect the respondents' evaluation responses for the admin, trainer, and client user interfaces respectively. The features and functionalities of the system are listed with the corresponding expected output. The respondents rated the actual output using a Pass/Fail criteria.

Table I. Respondent Responses for the AdminUser Interface

\begin{tabular}{|c|c|c|}
\hline \multicolumn{3}{|c|}{ Before the Training } \\
\hline User: ADMIN & Expected Output & $\begin{array}{l}\text { Actual } \\
\text { Output }\end{array}$ \\
\hline Adds client categories, addresses & $\begin{array}{l}\text { The application must be able to save client categories to the } \\
\text { database }\end{array}$ & Passed \\
\hline Adds training categories, training programs & $\begin{array}{l}\text { The application should save training categories and training } \\
\text { program to the database }\end{array}$ & Passed \\
\hline $\begin{array}{l}\text { Registers qualified Trainers \& assigns } \\
\text { training programs }\end{array}$ & $\begin{array}{l}\text { The application must be able to save trainers and assign } \\
\text { training programs to the trainers. }\end{array}$ & Passed \\
\hline $\begin{array}{l}\text { Sets training schedule } \\
\text { (Sends notifications to trainers and clients) }\end{array}$ & $\begin{array}{l}\text { The application can add training schedule and sends } \\
\text { notification to the client and trainers about the details of the } \\
\text { training. }\end{array}$ & Passed \\
\hline $\begin{array}{l}\text { Prints Master List of confirmed training } \\
\text { participants }\end{array}$ & $\begin{array}{l}\text { The application should be able to print master list of the } \\
\text { client who confirmed the attendance of the said training. }\end{array}$ & Passed \\
\hline \multicolumn{3}{|c|}{ During the Training } \\
\hline $\begin{array}{l}\text { Prints Master List of confirmed training } \\
\text { participants }\end{array}$ & $\begin{array}{l}\text { The application should be able to print master list of the } \\
\text { client who confirmed the attendance of the said training. }\end{array}$ & Passed \\
\hline \multicolumn{3}{|c|}{ After the Training } \\
\hline Terminates training program & $\begin{array}{l}\text { The application should be able to terminate the finished } \\
\text { training. }\end{array}$ & Passed \\
\hline $\begin{array}{l}\text { Upload attachments such as MOA, } \\
\text { Training Design, Attendance sheet, Photos, } \\
\text { etc. }\end{array}$ & $\begin{array}{l}\text { The application can save the attachment documents of the } \\
\text { training. }\end{array}$ & Passed \\
\hline Views/Prints Evaluation Results & $\begin{array}{l}\text { The application can view and print the evaluation result of } \\
\text { the training. }\end{array}$ & Passed \\
\hline
\end{tabular}


Table I. Respondent Responses for the TrainerUser Interface

\begin{tabular}{|c|c|c|}
\hline \multicolumn{3}{|c|}{ Before the Training } \\
\hline User: TRAINER & Expected Output & Actual Output \\
\hline Logs in to account & The user can log-in to the application. & Passed \\
\hline Confirms trainer/lecturer tasks & $\begin{array}{l}\text { The application sends notification and the trainers } \\
\text { confirms the notification. }\end{array}$ & Passed \\
\hline $\begin{array}{l}\text { Prints Master List of confirmed training } \\
\text { participants }\end{array}$ & $\begin{array}{l}\text { The application should be able to print master list of the } \\
\text { client who confirmed the attendance of the said training. }\end{array}$ & Passed \\
\hline \multicolumn{3}{|c|}{ During the Training } \\
\hline $\begin{array}{l}\text { Prints Master List of confirmed training } \\
\text { participants }\end{array}$ & $\begin{array}{l}\text { The application should be able to print master list of the } \\
\text { client who confirmed the attendance of the said training. }\end{array}$ & Passed \\
\hline \multicolumn{3}{|c|}{ After the Training } \\
\hline $\begin{array}{l}\text { Views Evaluation Results } \\
\text { Download training attachments for } \\
\text { personal or accreditation use }\end{array}$ & $\begin{array}{l}\text { The application can view and print the evaluation result } \\
\text { of the training. }\end{array}$ & Passed \\
\hline
\end{tabular}

Table I. Respondent Responses for the TrainerUser Interface

\begin{tabular}{|c|c|c|}
\hline \multicolumn{3}{|c|}{ Before the Training } \\
\hline User: CLIENT & Expected Output & Actual Output \\
\hline Registers profile & The client can registers his/her profile to the application & Passed \\
\hline $\begin{array}{l}\text { Conveys interest on training program } / \mathrm{s} \text { (submits } \\
\text { training need) }\end{array}$ & $\begin{array}{l}\text { The client can convey his/her interest to the training } \\
\text { offered }\end{array}$ & Passed \\
\hline Confirms attendance to scheduled training & $\begin{array}{l}\text { The client can confirm the attendance after the notification } \\
\text { sent by the application for the attendance }\end{array}$ & Passed \\
\hline \multicolumn{3}{|c|}{ During the Training } \\
\hline (Attends training) & & Passed \\
\hline \multicolumn{3}{|c|}{ After the Training } \\
\hline $\begin{array}{l}\text { Evaluates training program attended } \\
\text { May convey interest again on the same training } \\
\text { program for future follow-up trainings. }\end{array}$ & $\begin{array}{l}\text { The client can evaluate the performance of the trainer, } \\
\text { venue and etc. after the training }\end{array}$ & Passed \\
\hline
\end{tabular}

\section{Conclusion}

The findings revealed that the TrainME can be an effective tool in the assessment of training needs as well as managing extension programs and activities. Respondents of the usability test agreed that they would like to use the system frequently; that the system is easy to use; that the various functions in the system were well integrated; that they imagine most people would learn to use the system very quickly and that they very confident using the system.

\section{Recommendations}

For future improvements, TrainME can be embedded with nice-to-haves features such as data analytics, opinion mining, and word cloud generation. Further, for a wider implementation, information dissemination may be conducted during Parents-Faculty Association meetings, Local Government sessions, and the like. 


\section{References}

[1] Brandy Klug (2017). An Overview of the System Usability Scale in Library Website and System Usability Testing. University of North Texas Health Science Center, Source:https://quod.lib.umich.edu/w/weave/12535642.0001.602?view=text;rgn=main

[2] John Brooke (2015). System Usability Scale: A Quick Usability Scoring Solution. Source: http://satoriinteractive.com/system-usabilityscale-a-quick-usability-scoring-solution-2/

[3] Camille S. Peres, Et.al. (2013). Validation of the system usability scale (SUS): SUS in the wild. Texas A\&M Health Science Center University of Houston, Clear Lake: Source: https://www.researchgate.net/publication/273297038_Validation_of_the_System_Usability_Scale_SUS

[4] McConnell, S. (2006). Software Estimation: Demystifying the Black Art. Microsoft Press. "Waterfall vs. Agile Methodology." 2008. Agile Introduction for Dummies. Retrieved August 13, 2010, Source: http://agileintro.wordpress.com/2008/01/04/waterfall-vs-agile-methodology/

[5] Robins, J. (2018) Learning Web Design: A Beginners's Guide to HTML, CSS, Javascript, and Web Graphics. San Francisco, CA: O'Reilly Media, Inc.

[6] Runeson, P., et.al. (2012) Case Study Research in Software Engineering Guidelines and Examples, Hoboken, New Jersey: John Wiley and Sons, Inc.

[7] Spurlock, J. (2013) Bootstrap: Responsive Web Development. USA: O’Reilly Media, Inc.

[8] Stephens, R. (2015) Beginning Software Engineering, IN: John Wiley \& Sons, Inc.

[9] Tatroe, K., et.al. (2013) Programming PHP: Creating Dynamic Web Pages $3^{\text {rd }}$ Edition. USA: O’Reilly Media, Inc.

[10] Tsui, F. and Karam, O. (2011) Essentials of Software Engineering, MA: Jones and Bartlett Publishers

[11] Documentation. Source:http://support.sas.com/resources/papers/proceedings12/194-2012.pdfhttps://www.developer.com/services/whatscoming-in-bootstrap-4.html

[12] Welling, L. and Thomson L. (2009) PHP and MySQL Web Development $4^{\text {th }}$ Edition. USA: Pearson Education Inc. 